\title{
Optimization of a Hybrid Ground Source Heat Pump using the Response
} Surface Method

\author{
Honghee Park ${ }^{1}$, Wonuk Kim ${ }^{1}$, Joo Seoung Lee ${ }^{1}$ and Yongchan Kim²* \\ ${ }^{1}$ Graduate School of Division of Mechanical Engineering, Korea University, Anam-Dong, Sungbuk-Gu, Seoul, \\ 136-713, Korea \\ ${ }^{2}$ School of Mechanical Engineering, Korea University, Anam-Dong, Sungbuk-Gu, Seoul, 136-713, Korea \\ * Corresponding author. Tel.: +82 23290 3366, Fax: +82 2921 5439, E-mail: yongckim@korea.ac.kr
}

\begin{abstract}
A hybrid ground source heat pump (HGSHP) has been recommended as a low cost alternative of a ground source heat pump (GSHP) which has higher initial costs with increasing the size of ground heat exchanger (GHX) for imbalanced load conditions. HGSHP systems incorporate both GHX and supplemental equipments, such as cooling towers and/or boilers. The main issues of HGSHP are the optimal size design and control strategies of supplemental equipments. The objective of this paper is to optimize the size and control strategies using an optimization methodology called as the response surface method (RSM) to decrease the system's total initial cost (IC) and/or life cycle cost (LCC) and/or annual energy use (AEU) of HGSHP systems. The simulation data used in this research was originated from Yavutzurk et al. and integrated with the RSM. Commercial software, which is Minitab 15, has been adopted to draw contour plots, surface plots and overlaid contour. With using response optimizer, the optimal size design and control strategies of supplemental equipments were determined individually and the results were compared with the results of Yavutzurk et al. The optimal size and control strategies have been successfully determined using the optimization tool of the RSM.
\end{abstract}

Keywords: Hybrid ground source heat pump, Supplemental equipment, Optimization, Response Surface Method

\section{Nomenclature}

EFT entering fluid temperature......................

ExFT exiting fluid temperature ........................

GHXL ground heat exchanger length...........ft $(m)$

IC initial cost...........................................\$

LCC life cycle cost .......................................\$

PV present value cost...............................\$

\section{Introduction}

The remarkable advantage of a ground source heat pump (GSHP) is its energy saving potential. The GSHP can save up to $50 \%$ of the energy that would be used by conventional systems [1]. The prominent disadvantage of GSHP is higher initial costs which make shortterm economics unattractive, although long-term economics is attractive because of lower operating costs caused by higher system performance. Furthermore, for imbalanced load conditions, it is inevitable to increase the size of ground heat exchanger (GHX) or the distance between adjacent GHX boreholes to postpone heat buildup caused by the difference between cooling and heating. A hybrid ground source heat pump (HGSHP) has been recommended as a low cost alternative of GSHP, which can reduce GHX size and give more efficient operation. The HGSHP can effectively balance the ground thermal loads by incorporating supplemental equipments, such as cooling towers and/or boilers into the GSHP system. The design and operation of HGSHP are more complex than GSHP. Fig. 1 shows the schematic diagram of HGSHP system comprising serial and parallel arrangement of GHX and supplement equipment such as cooling tower and/or boiler. In this paper, the comparison between serial and parallel arrangement would not be conducted.

ASHRAE [2] sizes the supplemental heat rejecter capacity based on the difference between monthly average heating and cooling loads of the building rather than the peak loads. General 


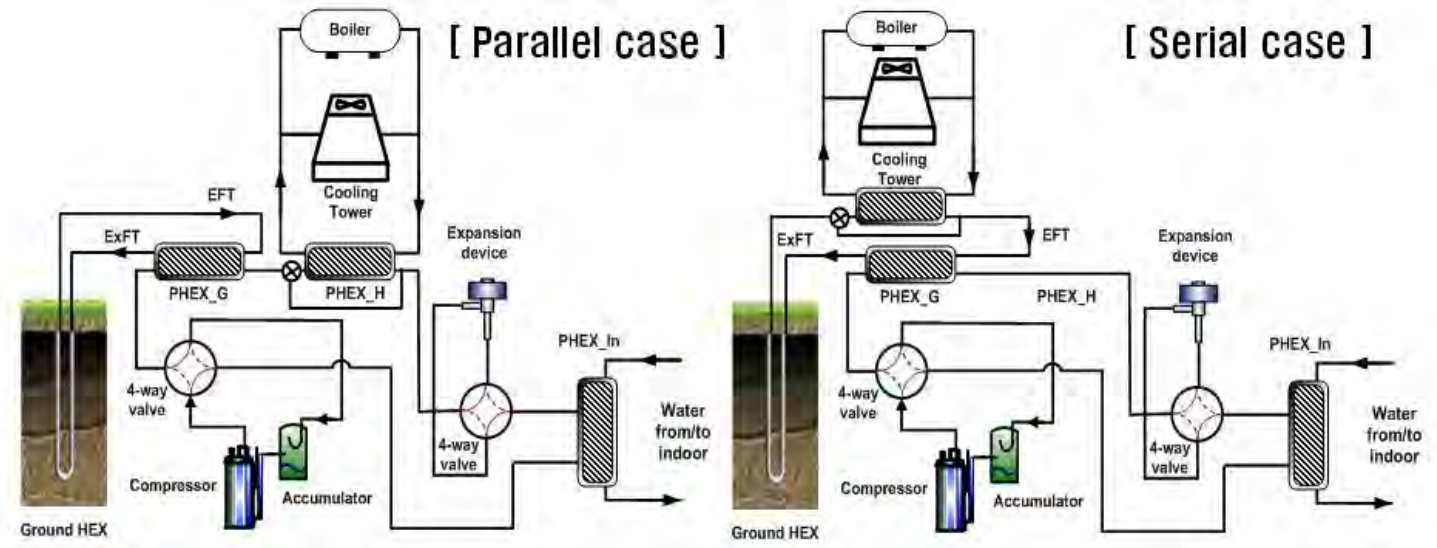

Fig. 1. Schematic diagram of hybrid ground source heat pump system.

guidelines for the integration of the heat rejecter into the system piping were presented. Kavanaugh and Rafferty [3] discuss HGSHP systems within the framework of GHX design alternatives. The sizing of the supplemental heat rejecter is based on the peak block load at the design condition. The nominal capacity is calculated based on the difference between the GHX length required for cooling and heating. Kavanaugh [4] revises and extends the existing design procedures as recommended in the above two publications. In addition, a control method is proposed for balancing the cooling and heating loads on the ground heat exchanger to limit long-term temperature rise. The revised procedure is applied to an office building in three climates, and initial cost and operating cost issues are discussed. Yavutzurk and Spitler [5] present a comparative study investigating several control strategies for HGSHP systems. The strategies investigated include set point control (operating the supplemental rejecter whenever the heat pump entering or exiting fluid temperature exceeds a set temperature, differential temperature control (operating the supplemental rejecter whenever the difference between heat pump fluid temperature and ambient air temperature exceeds set value), and operation of the supplemental rejecter to remove heat from the GHX field during nighttime hours. A 20-year life-cycle cost (LCC) analysis is conducted to compare each control strategy. Singh and Foster [6] explored first-cost savings resulting from HGSHP designs in two building-an office building and an elementary school. Ramamoorthy et al. [7] reported on a similar study that used a cooling pond as a supplemental heat rejecter. Using a differential temperature control strategy, a limited optimization of GHX size and pond size was performed. Chiasson and Yavutzurk [8] used the same system simulation approach to identify scenarios where the HGSHP system with a supplemental heat source is beneficial, in particular schools in heating-dominated climates, where the school was not operated during the summer. The supplemental heat sources investigated were solar thermal collectors and the approach was shown to be economically feasible.

Therefore, the main issues of HGSHP are the optimal size design and control strategies of supplemental equipments to minimize total initial cost or life-cycle cost or operating cost with satisfying designed range of entering or exiting fluid temperature to or from heat pump respectively which assures high performance of HGSHP. To size design of supplemental equipment depends on the size of GHX and its operating hours, and it means that smaller supplemental equipment should operate itself for longer hours. To size supplemental equipments and select its control strategies are coupled.

The objective of this paper is to optimize the size and control strategies using an optimization methodology called as the response surface method (RSM) to decrease the system's total 
initial cost (IC) and/or life cycle cost (LCC) and/or annual energy use (AEU) of HGSHP systems.

\section{Optimization Method}

\subsection{Control Strategies}

The strategies investigated include 3 kinds of control logics. Set point control (Control 1) means that the cooling tower is activated when the heat pump entering or exiting fluid temperature exceeds a set temperature such as 96.5F (35.8C). Differential temperature control (Control 2) means that the supplemental rejecter is operated whenever the difference between heat pump fluid temperature and ambient air temperature exceeds set value such as $3.6 \mathrm{~F}$ (2.0C) and is turned off when the difference is less than 2.7F (1.5C). Cool storage control (Control 3) means that the cooling tower is operated during nighttime hours to remove heat from the GHX field. For more detailed information, it could be found out in Yavutzurk and Spitler [5].

\subsection{Simulated data used}

This paper focused on the adoption of RSM as optimization method of HGSHP and so previously published data was used not to verify the building simulation results and to decide whether it is possible to solve this kind of optimization problem with RSM method or not. Used simulation data from TRNSYS simulation were originated from Yavutzurk and Spitler [5] of which building's total area is approximately 14,205 $\mathrm{ft}^{2}\left(1320 \mathrm{~m}^{2}\right)$. A 20-year life-cycle cost (LCC) analysis is conducted to compare each control strategy. The detailed information about the annual building loads was skipped. The simulated data is summarized in Table 1.

\subsection{RSM method and Objective function}

RSM is a kind of optimization methodology determining the range of main factors for optimizing responses and statistical approximation method for coupled design factors problem. Using minitab software, all RSM process can be conducted and several kinds of plots can be drawn. First of all, the definition of design factors and responses should be conducted. In this paper, determined design factors are ground heat exchanger length (GHXL) and control

Table 1. Simulated data used.

\begin{tabular}{ccccc}
\hline Control & $\begin{array}{c}\text { GHXL } \\
\text { ft(m) }\end{array}$ & $\begin{array}{c}\text { Total Initial } \\
\text { Costs(\$) }\end{array}$ & $\begin{array}{c}\text { Total Present } \\
\text { Value Costs(\$) }\end{array}$ & $\begin{array}{c}\text { Annual Energy } \\
\text { Use(kWh) }\end{array}$ \\
\hline \multirow{2}{*}{1} & $3000(914)$ & 26,662 & 46,075 & 24,179 \\
& $2625(800)$ & 23,036 & 40,783 & 22,200 \\
& $2250(686)$ & 19,505 & 35,493 & 19,913 \\
\hline \multirow{2}{*}{2} & $3000(914)$ & 22,427 & 38,438 & 19,941 \\
& $2625(800)$ & 19,774 & 35,254 & 19,230 \\
& $2250(686)$ & 17,195 & 32,171 & 18,563 \\
\hline \multirow{3}{*}{3} & $3000(914)$ & 21,272 & 41,845 & 25,623 \\
& $2625(800)$ & 18,175 & 37,259 & 23,800 \\
& $2250(686)$ & 15,078 & 32,672 & 21,914 \\
\hline
\end{tabular}


Table 2. Coefficients of response surface regression.

Coefficients

\begin{tabular}{|c|c|c|c|}
\hline \multirow{2}{*}{ Terms } & \\
\hline & $\begin{array}{c}\text { Total Initial } \\
\text { Costs }(\$)\end{array}$ & $\begin{array}{c}\text { Total Present } \\
\text { Value Costs }(\$) \\
\end{array}$ & $\begin{array}{c}\text { Annual Energy } \\
\text { Use(kWh) }\end{array}$ \\
\hline Constant & 4417.81 & 19752.2 & 17924.8 \\
\hline a (GHXL) & 8.40058 & 12.4643 & 6.14636 \\
\hline b (CONTROL) & -4061.50 & -14267.7 & -13042.8 \\
\hline c $(\mathrm{GHXL} * \mathrm{GHXL})$ & 0.000217625 & 0.00018660 & $-2.37487 \mathrm{E}-04$ \\
\hline d (CONTROL*CONTROL) & 825.103 & 3742.74 & 3714.60 \\
\hline e (GHXL*CONTROL) & 0.642000 & -0.939333 & -0.371333 \\
\hline
\end{tabular}

strategies with which supplemental equipment such as cooling tower is operated, and selected responses are the size of supplemental equipment, total initial costs, total present value costs and annual energy use. The objective function was defined as minimization of total initial costs and/or total present value costs and/or annual energy use. After analyzing design of experiment, response surface analysis was conducted and several kinds of plots such as contour plots, surface plots and overlain plots for multiple responses were drawn as well as response surface regression. Finally, the optimized values of GHXL and Control strategy were obtained to satisfy the objective function.

\section{Results and Discussions}

\subsection{Response surface regression}

Response surface regression was conducted using software of Minitab 15 as shown in Eq. 1. The regression curves were deducted in terms of 'GHXL' and 'CONTROL' comprising second order terms such as 'GHXL*GHXL' and 'CONTROL* CONTROL' and interaction term of 'GHXL* CONTROL' for the responses (Y) such as total initial cost, total present value costs and annual energy use. The regression coefficients are listed in Table 2. The calculated R-Square values of total initial costs, total present value costs and annual energy use are $99.28 \%, 97.61 \%, 96.51 \%$ respectively.

$$
\begin{aligned}
\mathrm{Y}= & \text { Constant }+\mathrm{a} \times(\mathrm{GHXL})+\mathrm{b} \times(\text { Control })+\mathrm{c} \times(\mathrm{GHXL} \times \mathrm{GHXL}) \\
& +\mathrm{d} \times(\text { Control } \times \text { Control })+\mathrm{e} \times(\mathrm{GHXL} \times \text { Control })
\end{aligned}
$$

\subsection{Surface plots and Contour plots}

As it is shown in Fig. 2, Surface plots and Contour plots for 3 responses were drawn. Contour plot is two dimensional and Surface plot is three dimensional. With these plots, optimization direction could be obtained. To decrease total initial costs, total present value costs and annual energy use, GHXL size should be decreased which means increasing cooling tower size in all cases. As for the control strategies, in the case of total initial costs, control strategy should approach Control 3 which means cool storage control to minimize total initial costs, and in the case of total present value costs, control strategy should come close to the middle point between Control 2 which means differential control and Control 2.5 which means the mixed control of 50\% Control 2 and 50\% Control 3 for minimizing total present value costs. As we can see, the control strategy for annual energy use should approach Control 1.8 to minimize annual energy use. 

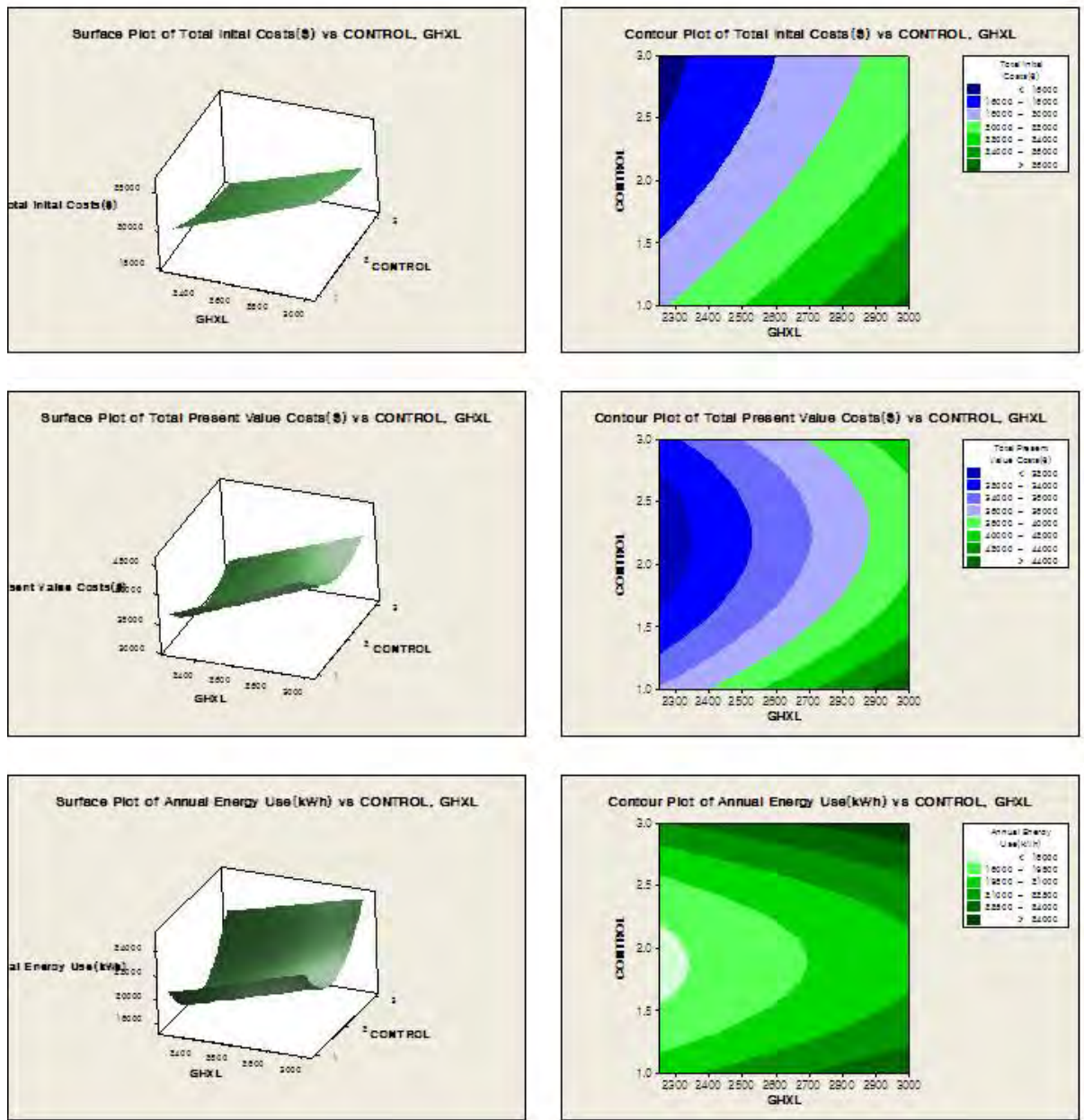

Fig. 2. Surface plots and Contour plots for 3 responses.

\subsection{Overlaid contour}

To draw overlaid contour, the ranges of 3 responses were determined as it is in Fig. 3 such as $15,000 \sim 18,000$ (\$) for total initial costs and 32,000 35,500 (\$) for total present value costs and 18,500 19,900 (kWh) for annual energy use.

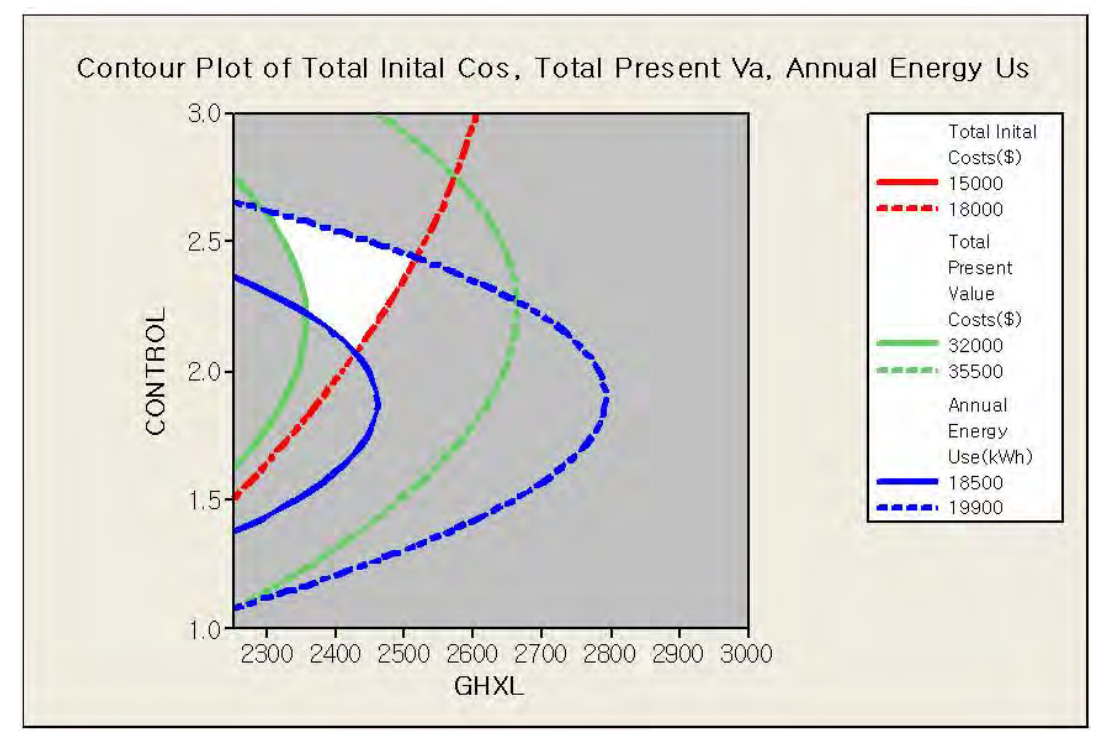

Fig. 3. Overlaid contour for 3 responses. 

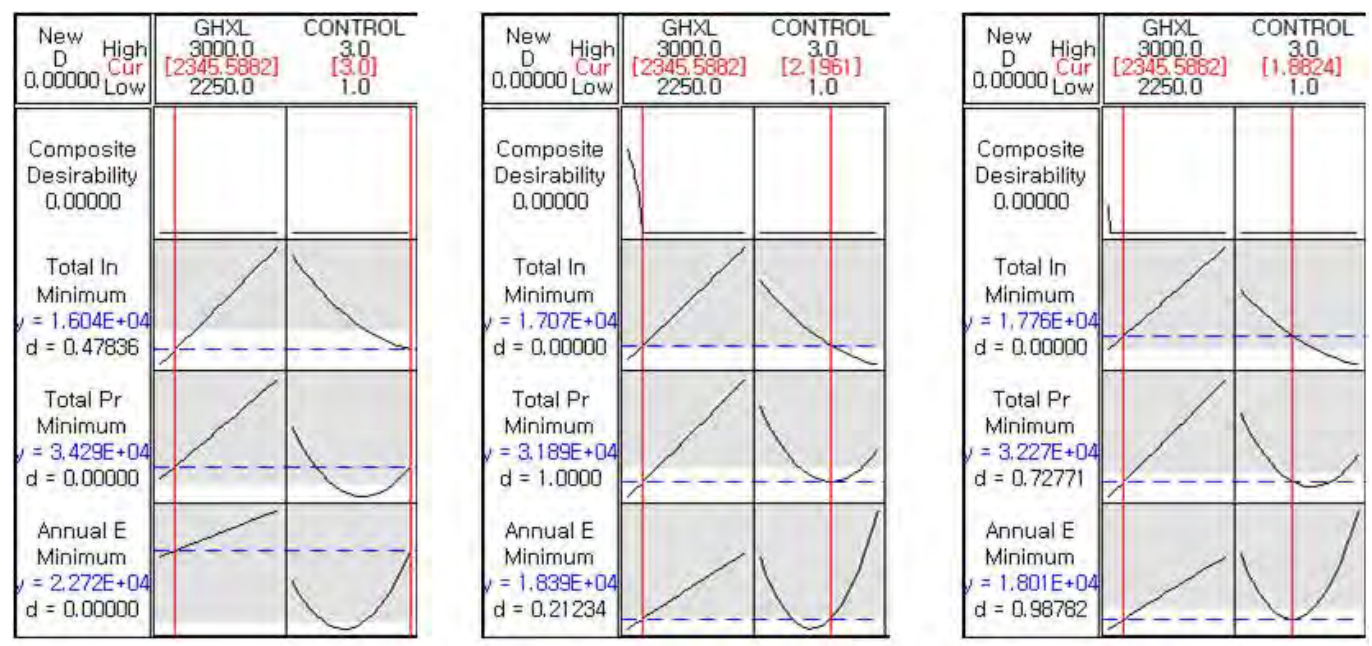

Fig. 4. The result of response optimizer for minimizing 3 responses

In Fig. 3, the bright region enclosed 3 pair of curves satisfies 3 conditions given and it means that the optimal values of factors and responses are within the bright region. For the purpose of determining optimum value of GHXL and Control to minimize individually each response, the response optimizer should be conducted.

\subsection{Results from Response optimizer}

In Fig. 4 the left figure presenting response optimizer result is for total initial costs and optimum value of GHXL and Control strategy are 2,345 ft $(715 \mathrm{~m}), 3.0$ respectively and minimum total initial cost is 16,040 \$. The middle figure is for total present value costs and optimum value of GHXL and Control strategy are 2,345 ft $(715 \mathrm{~m}), 2.2$ respectively and minimum total present value cost is 31,890 \$. The right figure is for annual energy use and optimum value of GHXL and Control strategy are 2,345 ft $(715 \mathrm{~m}), 1.9$ respectively and minimum annual energy use is $18,010(\mathrm{kWh})$. The individual desirability and composite desirability were checked. These results are listed in Table 3 and compared with the previous results from Yavutzurk and Spitler [5]. With RSM, 17\% decrease of total present value costs and $10 \%$ of annual energy use compared with Yavutzurk and Spitler [5] were obtained, though there was $7 \%$ increase of total initial costs.

\section{Conclusions}

The objective of this paper was to optimize the size and control strategies using an optimization methodology called as the response surface method (RSM) to decrease the system's total initial cost and/or life cycle cost and/or annual energy use of HGSHP systems.

Table 3. Results Comparison between RSM and Yavutzurk and Spitler [5].

\begin{tabular}{cccc}
\hline Terms & RSM & Yavutzurk and Spitler [5] & Difference $( \pm \%)$ \\
\hline $\begin{array}{c}\text { Total Initial } \\
\text { Costs }(\$)\end{array}$ & $16,140(\$)$ & $15,078(\$)$ & $+1,062(+7 \%)$ \\
\hline $\begin{array}{c}\text { Total Present } \\
\text { Value Costs }(\$)\end{array}$ & $31,890(\$)$ & $38,438(\$)$ & $-6,548(-17 \%)$ \\
\hline $\begin{array}{c}\text { Annual Energy } \\
\text { Use }(\mathrm{kWh})\end{array}$ & $18,010(\mathrm{kWh})$ & $19,941(\mathrm{kWh})$ & $-1,931(-10 \%)$ \\
\hline
\end{tabular}


In this paper, determined design factors were ground heat exchanger length (GHXL) and control strategies with which supplemental equipment such as cooling tower is operated, and selected responses were the size of supplemental equipment, total initial costs, total present value costs and annual energy use. The objective function was defined as minimization of total initial costs and/or total present value costs and/or annual energy use. Using minitab software, all RSM process was conducted and response surface regression and several kinds of plots such as surface plots, contour plots and overlaid contour were drawn.

With RSM, $17 \%$ decrease of total present value costs and $10 \%$ of annual energy use compared with Yavutzurk and Spitler [5] were obtained, though there was 7\% increase of total initial costs. The optimal size and control strategies have been successfully determined using the optimization tool of the RSM.

\section{Acknowledgement}

This research was sponsored by the Korea Institute of Energy and Resources Technology Evaluation and Planning (Grant No. 2008NBLHME0900002008).

\section{References}

[1] United States Department of Energy, Energy Efficiency and Renewable Energy homepage, September 2007, http://www1.eere.energy.gov/geothermal/history.html.

[2] ASHRAE, Commercial/institutional ground-source heat pumps engineering manual, Atlanta: American Society of Heating, Refrigerating and Air-Conditioning Engineers, Inc., 1995.

[3] S.P. Kavanaugh and K. Rafferty, Ground-source heat pumps: Design of geothermal systems for commercial and institutional buildings, Atlanta: American Society of Heating, Refrigerating and Air-Conditioning Engineers, Inc., 1997.

[4] S.P. Kavanaugh, A design method for hybrid ground source heat pumps, ASHRAE Transactions 104 (2), 1998, pp. 691-698.

[5] C. Yavuzturk and J.D. Spitler, Comparative Study to Investigate Operating and control Strategies for Hybrid Ground Source Heat Pump Systems Using a Short Time-step Simulation Model, ASHRAE Transactions 106(2), 2000, pp.192-209.

[6] J.B. Singh and G. Foster, Advantages of Using the Hybrid Geothermal Option, The Second Stockholm International Geothermal Conference, The Richard Stockton College of New Jersey, 1998.

[7] M. Ramamoorthy et al., Optimal Sizing of Hybrid Ground- Source Heat Pump Systems that use a Cooling Pond as a Supplemental Heat Rejecter - A System Simulation Approach, ASHRAE Transactions 107(1), 2001, pp. 26-38.

[8] A.D. Chiasson and C. Yavuzturk, Assessment of the Viability of Hybrid Geothermal Heat Pump Systems with Solar Thermal Collectors, ASHRAE Transactions 109(2), 2003, pp. 487-500. 